\title{
Co-Simulation of an Inverter Fed Permanent Magnet Synchronous Machine
}

\author{
Gergely Máté Kiss (Doctoral Student, Budapest University of Technology and Economics), \\ István Vajda (Professor, Óbuda University)
}

\begin{abstract}
Co-simulation is a method which makes it possible to study the electric machine and its drive at once, as one system. By taking into account the actual inverter voltage waveforms in a finite element model instead of using only the fundamental, we are able to study the electrical machine's behavior in more realistic scenario. The recent increase in the use of variable speed drives justifies the research on such simulation techniques. In this paper we present the co-simulation of an inverter fed permanent magnet synchronous machine. The modelling method employs an analytical variable speed drive model and a finite element electrical machine model. By linking the analytical variable speed drive model together with a finite element model the complex simulation model enables the investigation of the electrical machine during actual operation. The methods are coupled via the results. This means that output of the finite element model serves as an input to the analytical model, and the output of the analytical model provides the input of the finite element model for a different simulation, thus enabling the finite element simulation of an inverter fed machine. The resulting speed and torque characteristics from the analytical model and the finite element model show a good agreement. The experiences with the co-simulation technique encourage further research and effort to improve the method.
\end{abstract}

Keywords - Finite element analysis; Permanent magnet motors; Simulation; Variable speed drives.

\section{INTRODUCTION}

The development of power electronics over the last years resulted in high quality and reliable switching devices such as the Insulated Gate Bipolar Transistor (IGBT). These devices enable creating high efficiency power converters of many different topologies. One of which is the Two Level Voltage Source Inverter (2L-VSI). The reliable, cost efficient design of the 2L-VSI can be driven with simple control techniques thus making it a number one choice for Variable Speed Drives (VSD) in the medium power range. This includes the vehicle drives. [1]

A VSD consist of not only the inverter but several other elements including a power source, filters and an electric machine. The basic concept was to use inverters to feed mass produced motors (mainly induction motors) or already available motors thereby allowing VSD application including torque, speed and position control. However these motors were not designed for inverter use. This results in inverter mode dependent excess losses or even oscillations in torque due to the harmonics produced by the inverter. Special rotating machines designed for inverter feeding can be found e.g. in Electric Vehicle (EV).
Therefore it is important to take into account the characteristics of the future inverter application in the motor's design process. This approach is a subject to ongoing studies [8]-[13]. The most common solution is to use Flux/Portunus or Matlab environments. These tools are inherently able to perform co-simulation. However they lack wide multiphysics capabilities and general flexibility of COMSOL which are necessary in case of special material characteristic (eg. superconductors) and when physics other than electromagnetics are also involved. Therefore the main objective of this work is to investigate the viability of a Matlab/Simulink and COMSOL based co-simulation method.

\section{THE MODELLING METHOD}

The concept is to use COMSOL finite element software and MATLAB/Simulink together. The COMSOL model is a fictitious motor and is responsible for the geometry and material dependent features and provides the motor data. Using the motor data a Simulink model is created including a Pulse Width Modulation (PWM) 2L-VSI model to feed the motor. The results of the Simulink simulation is then stored. The stored data is then fed back to COMSOL motor model which runs through the data points of the Simulink simulation. The process is illustrated in Fig. 1.

\section{THE MATLAB/SIMULINK MODEL}

The Simulink model consists of a 2L-VSI inverter model, a speed controller with underlying torque and current control and a motor model. The motor model is a stock Simulink block, since it was found suitable for this work. The controller's parameters were calculated based on the motor parameters (electrical and mechanical time constants). The controller synthetizes the control signal for the 2L-VSI which uses the Space Vector PWM (SVPWM) modulation.

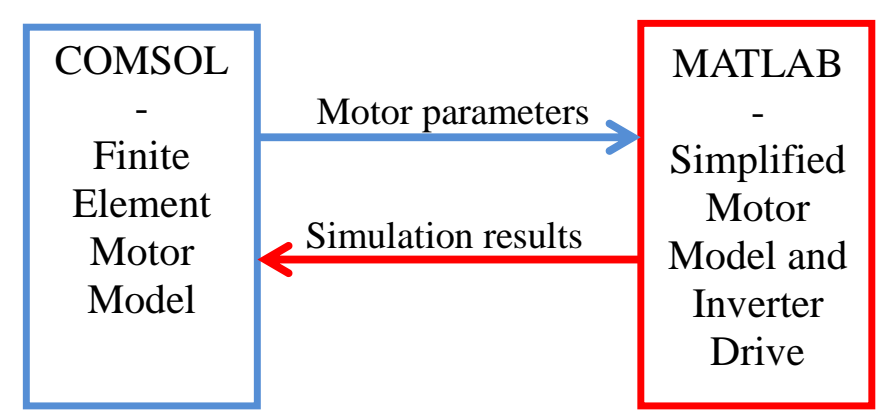

Fig. 1. The scheme of the described modeling method. 


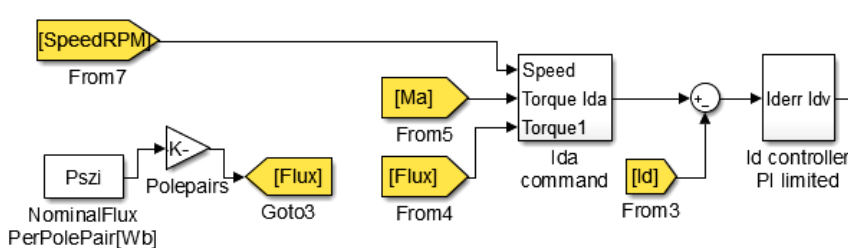

PerPolePair[Wb]
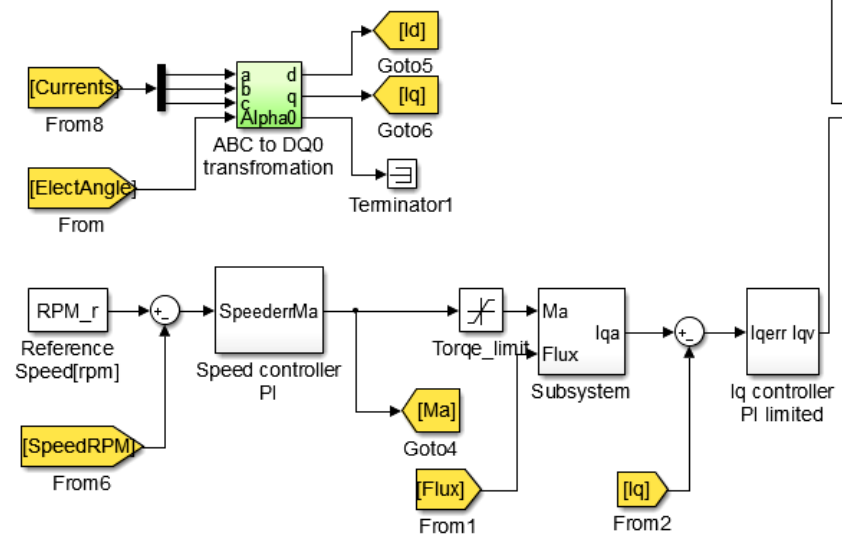

Fig. 2. Simulink model, part 1 (controllers).

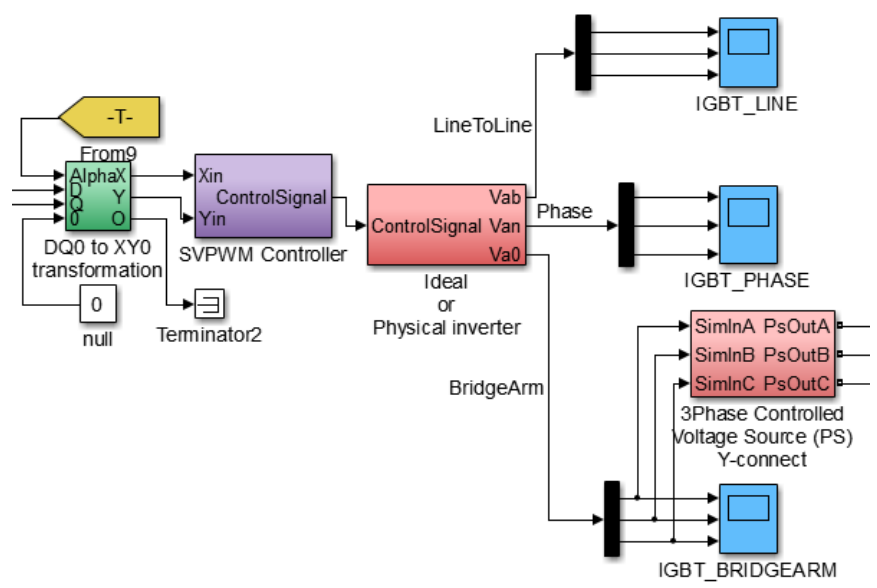

Fig. 3. Simulink model, part 2, (SVPWM inverter and scopes). The ideal inverter mode voids dead times and switching losses while physical inverter includes them. The simulation runs much faster using the ideal inverter.

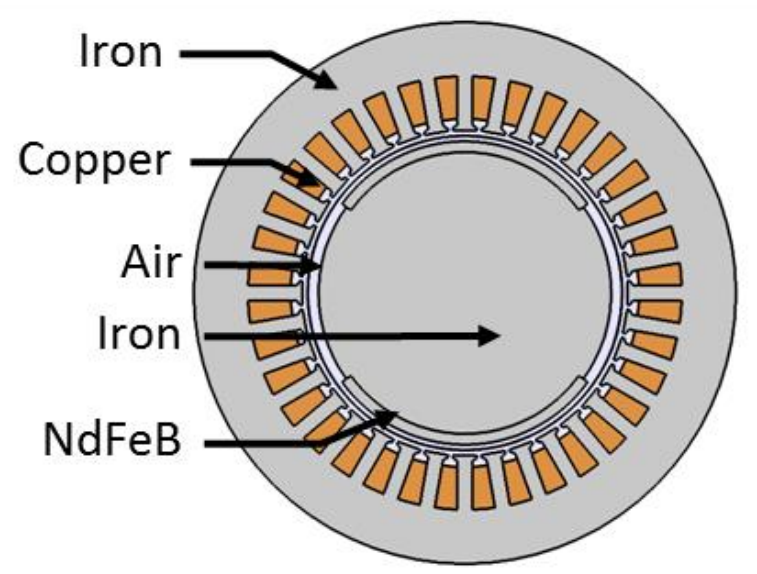

Fig. 4. PMSM model, materials.
The block diagram of the inverter is covered in Fig. 2 and Fig. 3. Nowadays SVPWM is a fairly popular technique for high performance and good efficiency VSD applications. For the 2L-VSI topology SVPWM is the most advantageous control technique for its long linear range and because it causes lower amount of loss in the motor than any other technique [2].

The most important parameters of the inverter operation are summarized in Table I.

\section{THE COMSOL MODEL}

The modelled machine is a 3-phase Permanent Magnet Synchronous Machine (PMSM) with a fictitious design suitable for simple investigations. The elements of the model are shown in Fig. 4. The motor's main parameters are summed up in Table II.

TABLE I.

INVERTER PARAMETERS

\begin{tabular}{|l|l|l|}
\hline Description & Parameter & Value \\
\hline Inverter switching frequency & $f_{P W M}$ & $2 \mathrm{kHz}$ \\
\hline DC supply voltage & $U_{D C}$ & $200 \mathrm{~V}$ \\
\hline Prescribed rotational velocity & $w_{a}$ & $2000 \mathrm{rpm}$ \\
\hline PWM technique & n.a. & SVPWM \\
\hline
\end{tabular}

TABLE II.

MOTOR PARAMETERS

\begin{tabular}{|l|l|l|}
\hline Description & Symbol & Value \\
\hline Outer diameter & $D_{k}$ & $100 \mathrm{~mm}$ \\
\hline Length & $L$ & $90 \mathrm{~mm}$ \\
\hline Air gap & $g$ & $2 \mathrm{~mm}$ \\
\hline Phase number & $m$ & 3 \\
\hline Winding connection type & n.a. & star \\
\hline Rated speed & n.a. & $3000 \mathrm{rpm}$ \\
\hline Rated power & n.a. & $5 \mathrm{~kW}$ \\
\hline Number of slots & $Q$ & 36 \\
\hline Number of poles & $p$ & 2 \\
\hline Round wire diameter (AWG 30) & $d_{w}$ & $0.255 \mathrm{~mm}$ \\
\hline Cross section of slot filled with copper & $A_{\text {slot }}^{\prime}$ & $27.575 \mathrm{~mm}{ }^{2}$ \\
\hline Number of turns & $N$ & 20 \\
\hline Electrical resistivity of copper & $\rho_{C u}$ & $1.68 \mathrm{e}-8 \Omega \mathrm{m}$ \\
\hline $\begin{array}{l}\text { Relative permeability of iron (linear } \\
\text { case) }\end{array}$ & $\mu_{r}$ & 200 \\
\hline Permanent magnet material & n.a. & NdFeB \\
\hline Magnet remanent flux density & $B_{r}$ & $1.2 \mathrm{~T}$ \\
\hline Density of iron & $\rho_{F e}$ & $7870 \mathrm{~kg} / \mathrm{m}^{3}$ \\
\hline Density of NdFeB magnets & $\rho_{N d F e B}$ & $7501.25 \mathrm{~kg} / \mathrm{m}^{3}$ \\
\hline & & \\
\hline
\end{tabular}




\section{A. Modelling Considerations}

The model is 2D, since radial flux PMSM machines can effectively be investigated in this representation. Also a $2 \mathrm{D}$ model is a lot less computationally expensive than a $3 \mathrm{D}$ model. The machine has 2 poles and 36 slots in its stator. The rareearth permanent magnets are considered to be surface mounted and covering $60 \%$ of the pole area. The permanent magnets are modelled taking into account their remanent flux density. The air gap is chosen to be rather small in order to match with realworld motor designs. The winding is considered to be of a distributed type and it consists of many thin parallel connected conductors instead of one conductor with a larger cross section. This way the occurring skin-effect can be neglected. Using the $2 \mathrm{D}$ representation of the machine however has a major drawback. That is it does not take into account the endwindings which make up for a large part of a motor phase resistance. This is highly undesirable. By modifying COMSOL's underlying equations an additional resistance can be included, that way the end-winding's resistance is in the model. The analytical formula to determine the resistance of a phase winding is:

$$
R_{p h}=\frac{Q}{m} \frac{L+D_{k} \pi}{A_{\text {slot }}^{\prime}} N \rho_{C u},
$$

where $A^{\prime}$ slot is the cross section area of one slot filled with copper and $\rho_{C u}$ is the electrical resistivity of copper, $Q$ is the slot number, $L$ is the motor's active length, $D_{k}$ is the stator outer diameter, $m$ is the phase number and $N$ is the winding's turn number. With this included the calculated resistivity of the motor is correct.

The stator at first is modelled as a nonlinear soft-magnetic material (soft iron). This way the maximum values of magnetic flux density is determined. Since the nonlinear model showed no saturation effects, the use of linear material model is possible. The linear material model is used to increase numerical stability and reduce solution time. The stator is also assumed to be stacked, therefore eddy-currents in the stator are also neglected. The model's meshing must be fine enough in order to enable precise calculations, especially in the air gap area. Fig. 5. illustrates a fraction of the finite element mesh.

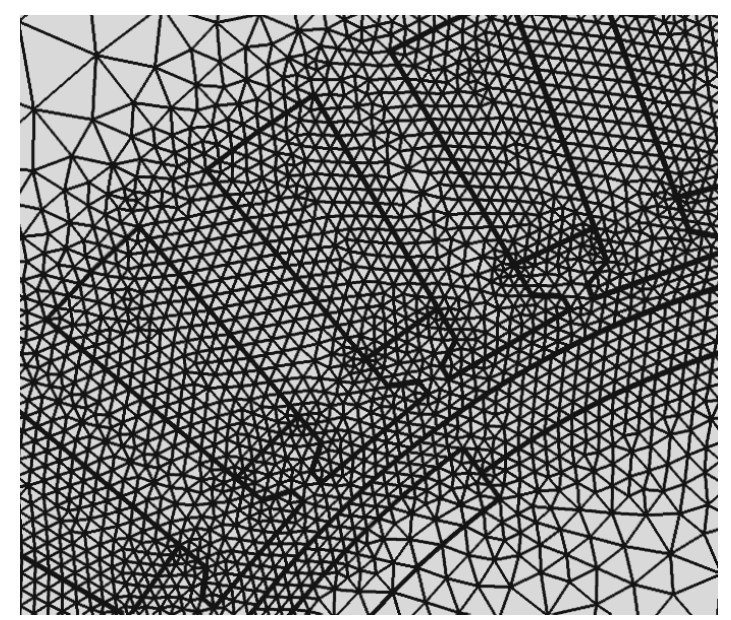

Fig. 5. The mesh distribution of the model. The mesh consist a total of 38508 elements.

\section{B. Simulation Goals}

The Simulink model presented in Section III requires that we find out the motor's certain electrical and mechanical parameters from the finite element model. The following information is required to setup the analytical model: induced voltage or back-EMF, winding's resistance, synchronous inductances in the direct (d) and quadrature (q) axis, rotor's moment of inertia.

They are not given, but resulting parameters obtained by running the simulation. For this the simulation has to be run in different ways. To determine the induced voltage the motor has to be run in open circuit mode, i.e. no currents are present in the windings. The inductances can be determined by locking the rotor aligned with the axis of a coil, then apply alternating voltage to two coil endings and study the current. Then repeat the procedure with rotor aligned perpendicular to the coil axis, like in the case illustrated in Fig. 4 for phase A's winding. Yet another method is to perform the before mentioned steps but instead of alternating current use direct current, and measure the time constant of transient of current. Here both methods are presented.

The winding resistance is calculated anyway, since COMSOL automatically does this calculation if the corresponding domains are set up as coils domains. For the moment of inertia the general formula is used in COMSOL:

$$
I_{z}=\int_{V} \rho(r) r^{2} d V,
$$

where $r$ is the point's coordinate and $\rho$ is the density at the given coordinate.

\section{Simulation Results}

The simulations are true time dependent studies with machine's nominal frequency chosen to be $f=50 \mathrm{~Hz}$. Therefore it is important to choose an adequately small time step so that the most accurate solution can be achieved without the simulation being too slow. For this purpose a time-step of $d t=55.555 \mu \mathrm{s}$ was an empirically tested, optimal choice. The first simulation finds the induced voltage and also the magnetic flux density map of the motor's cross section. The results are shown in Fig. 6 and Fig. 7.

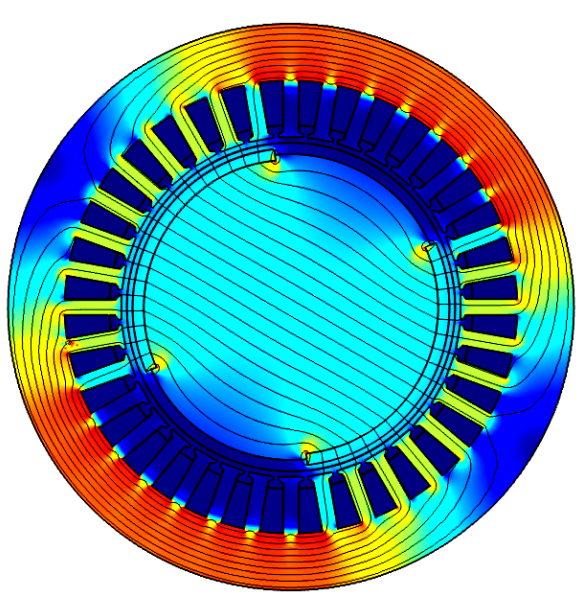

Fig. 6. The flux density distribution of the motor. The highest value can be observed at corner of the magnet, where $B_{\max }=1.6 \mathrm{~T}$. 


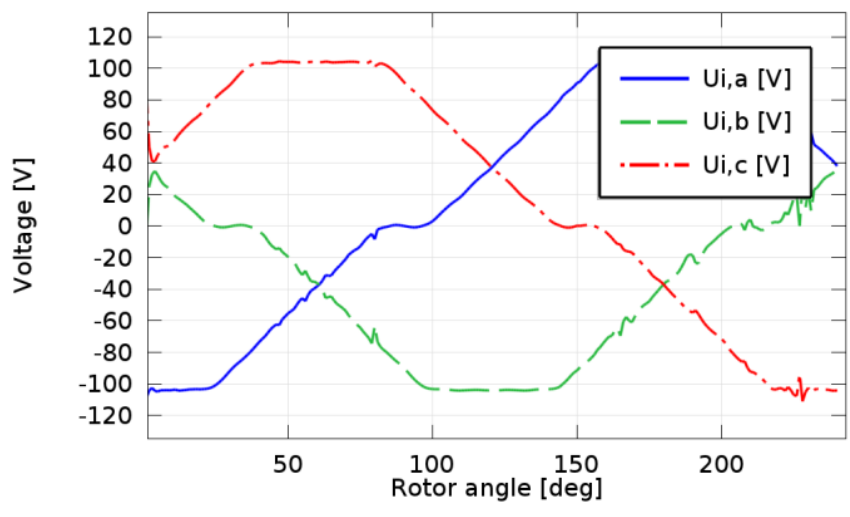

Fig. 7. The induced voltage for each phase, $U_{i, \max }=104 \mathrm{~V}$.

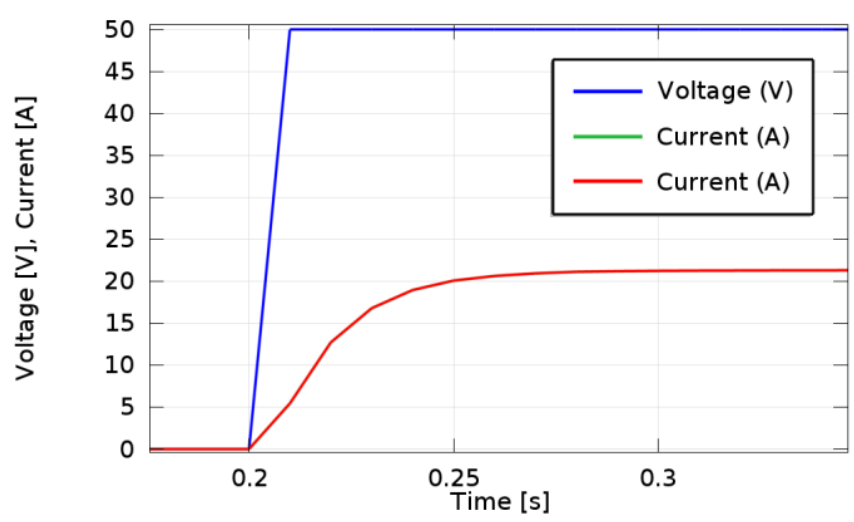

Fig. 8. The voltage excitation is a step function. The time transient currents are overlapping, which means that the machine is round rotor, i.e. $L_{d}=L_{q}$. The time constant $T$ can be read from the figure, $T=0.04 \mathrm{~s}$.

It is worth noticing that the induced voltage is not sinusoidal, but trapezoidal. The inductance is calculated at two rotor positions with the time transient method as described in the previous subsection. The current transient is illustrated in Fig. 8.

The inductance is then calculated using the time constant and the previously determined resistance:

$$
T=L / R \longrightarrow L=T R=0.04 \cdot 1.173=46.91 \mathrm{mH} .
$$

This value can be verified by the other, alternating currentbased method illustrated in Fig. 9 and Fig. 10. Using the time functions the impedance could be calculated in both rotor positions and from that the inductance could be obtained. Since both methods gave the same result as shown in Eq. 3, the detailed description of this second method is void.

The calculated parameters and their values are summarized in Table III. Using these it is now possible to run the Simulink based simulations.

\section{V.VSD SIMULATION IN SIMULINK}

Applying the data found in Table I and III to the Simulink VSD model described in Section III it is now ready to run. The Simulink model shows how the motor from the finite element model would work, if used in a VSD. The Simulink model's results are the motor phase currents, the motor's speed and

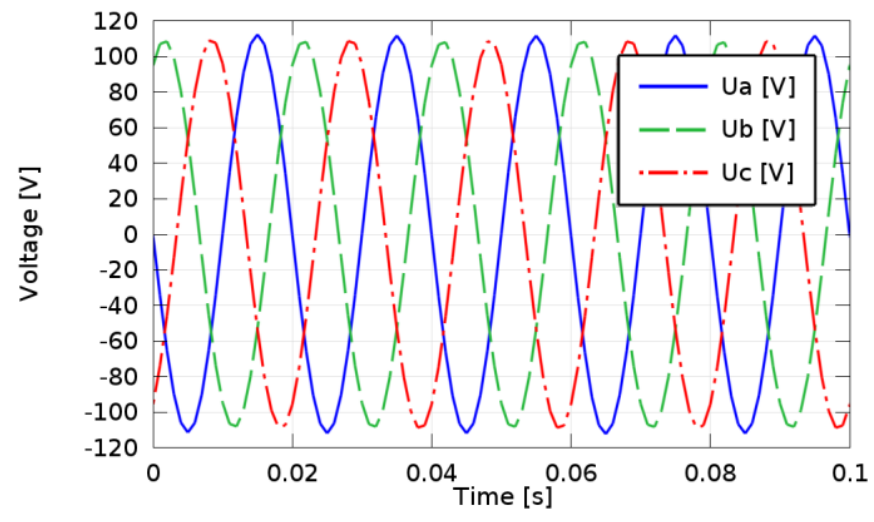

Fig. 9. The alternating phase voltage excitation applied on the locked rotor machine.

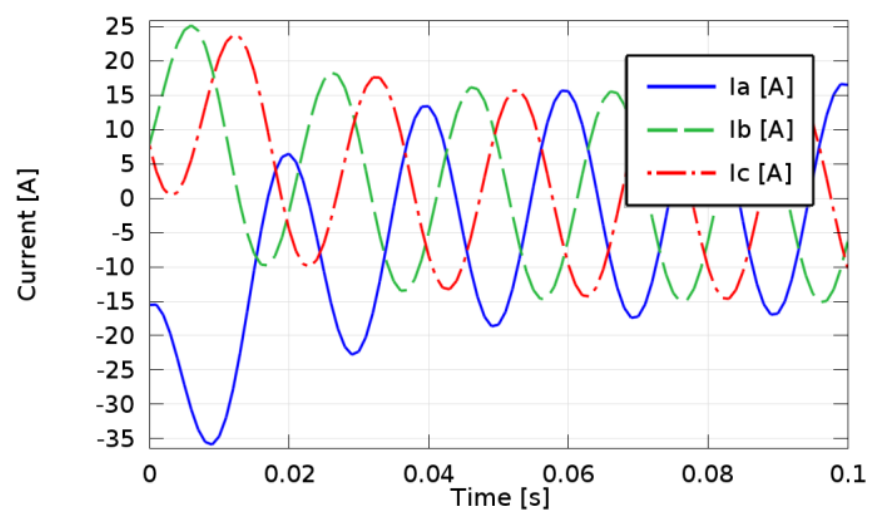

Fig. 10. The resulting phase currents.

the electromagnetic torque. The time functions of these quantities are shown in Fig. 11. For the simulation a reference speed of $2000 \mathrm{rpm}$ was chosen, two-third of the motor's nominal frequency.

This is to ensure that the machine operates in the normal operating range, i.e. not in field-weakening mode.

The switching frequency of the inverter (PWM frequency) is set to a constant value of $2 \mathrm{kHz}$. This results in a relatively high frequency modulation ratio:

$$
m_{r}=\frac{w_{a}}{f_{P W M}}=60 .
$$

This is not only large number, but also a multiple of three. For 3-phase system this is advantageous: even the first order harmonics appear far in the spectrum and due to the symmetry of the 3-phase system many harmonics are cancelled out [2],[3]. Fig. 12 shows the resulting phase voltage waveform of the motor.

TABLE III.

CAlculated Motor Parameters

\begin{tabular}{|l|l|l|}
\hline Description & Symbol & Value \\
\hline Resistance of one phase winding & $R_{p h}$ & $1.173 \Omega$ \\
\hline Inductance & $L$ & $46.91 \mathrm{mH}$ \\
\hline Induced voltage, peak & $U i$ & $104 \mathrm{~V}$ \\
\hline Rotor's moment of inertia & $I_{z}$ & $0.00064 \mathrm{~kg} \cdot \mathrm{m}^{2}$ \\
\hline
\end{tabular}



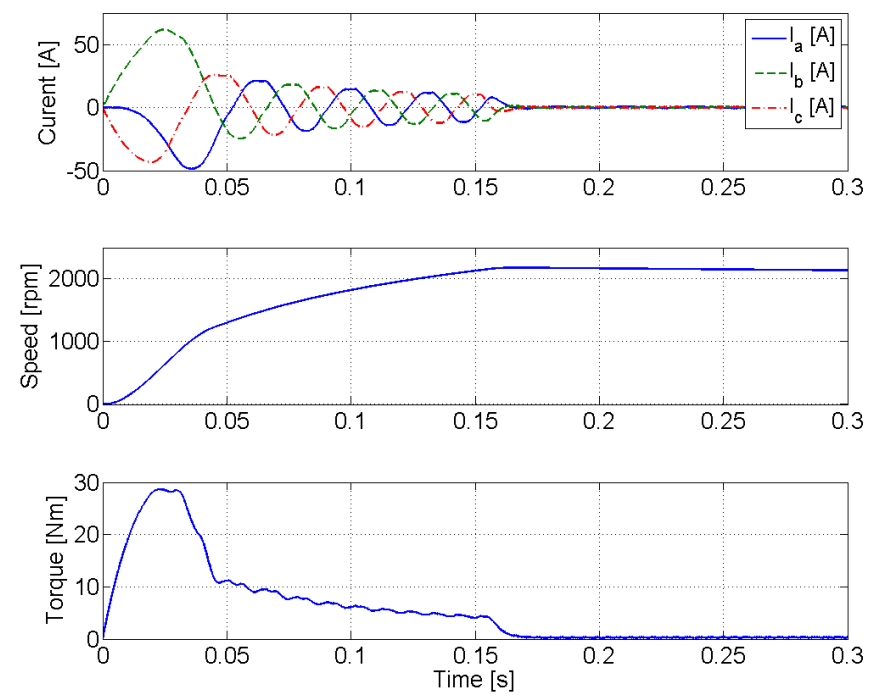

Fig. 11. Phase current, speed and torque of the motor during a controlled startup in the Simulink model.
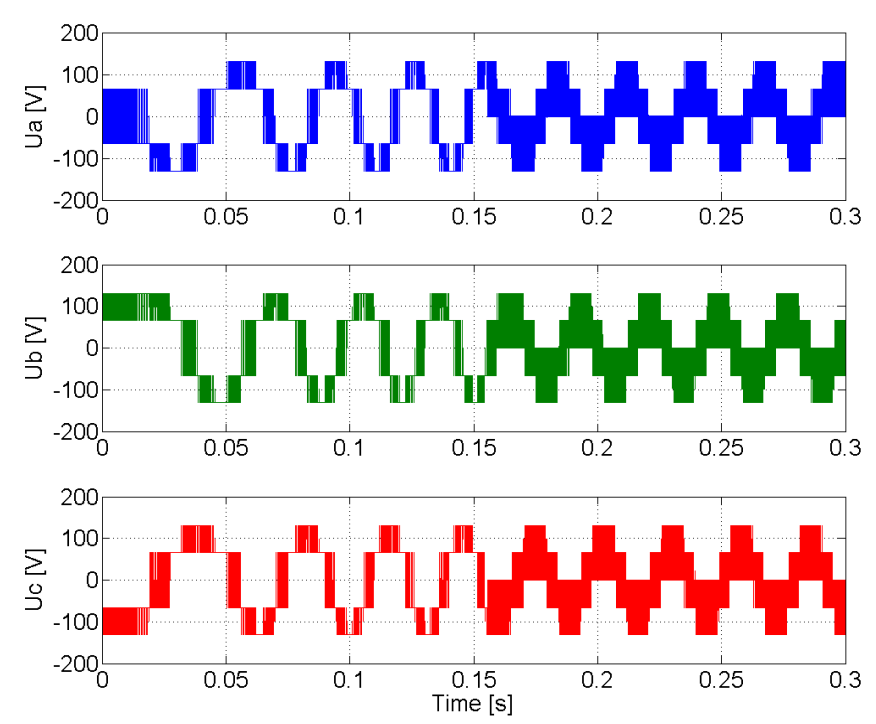

Fig. 12. Phase voltages of the motor with inverter operation in the Simulink model.

\section{COUPLING OF The Models}

With the numerical simulation data form the Simulink model now it is possible to couple the Simulink and the COMSOL models. In this investigation the inverter voltages and the rotational speed from the Simulink model is coupled to the COMSOL model. That is, the output of the inverter is now the excitation of windings of the finite element model. This indicates that the coupling between the models is passive. Simulink and COMSOL are not used simultaneously. To allow COMSOL to use the previously stored Simulink output data some special functions had to be written which ensure, that COMSOL can always access data matching its current simulation time. Even if COMSOL's prescribed time stepping is exactly the same as the Simulink model's it cannot be ensured, that the exact same time samples are taken. Especially because COMSOL (just like Simulink) sometimes takes substeps in case the solution is hard to converge.

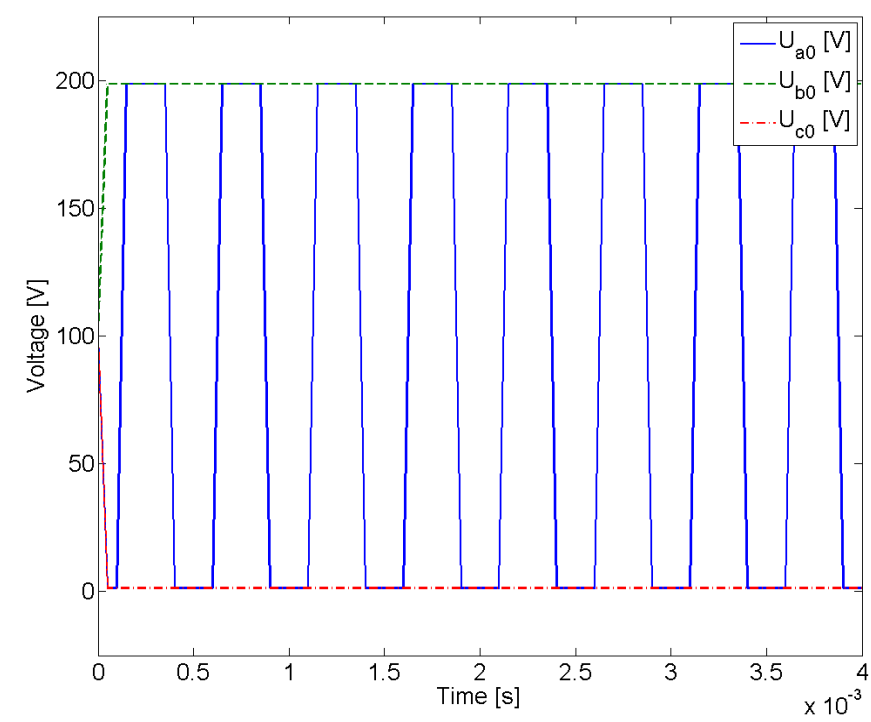

Fig. 13. The 3-phase inverter output voltages appearing on the voltage source of the finite element model in COMSOL.

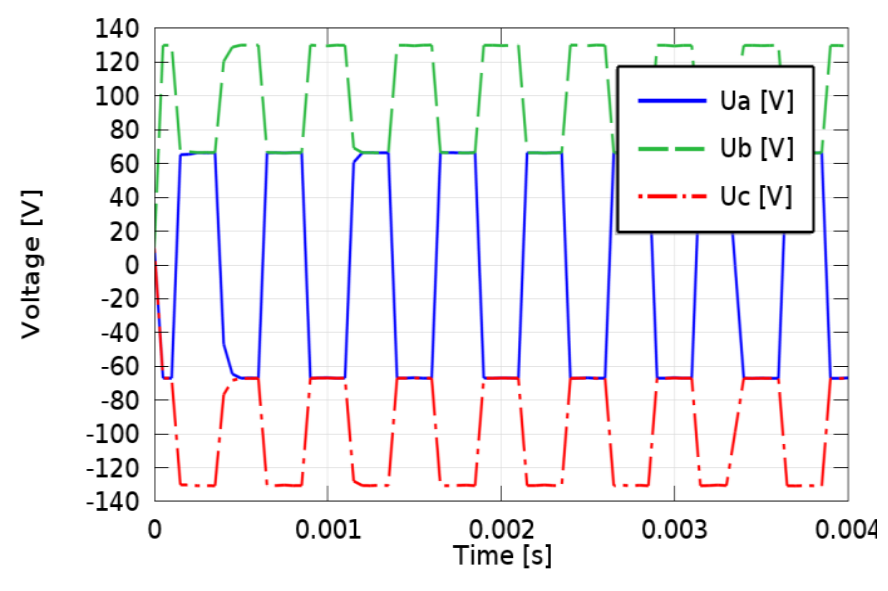

Fig. 14. The phase voltages on the stator windings in COMSOL. These voltages appear on the winding of the COMSOL motor model as the result of the inverter excitation waveform originated from the Simulink model.

\section{A. Results Of Coupled Simulation}

With this in mind a time step of one-tenth the PWM frequency is chosen: $d t=1 / 2000 / 10=5 \mu \mathrm{s}$. The iron is set to the linear model to save time. The total amount of simulated time is $T_{\max }=8.6 \mathrm{~ms}$. The results are shown in Fig. 13 to 15 .

\section{B. Comparison Of Simulink And Coupled COMSOL Results}

The coupled simulation worked satisfactory. Some finetuning is still needed, but the results are in good agreement with each other. It can be concluded that there are no numerical issues, i.e. taking of different time steps from the Simulink simulation does not result in problems. For comparison a close-up on the voltages and torque is provided in Fig. 16 and 17 respectively. 


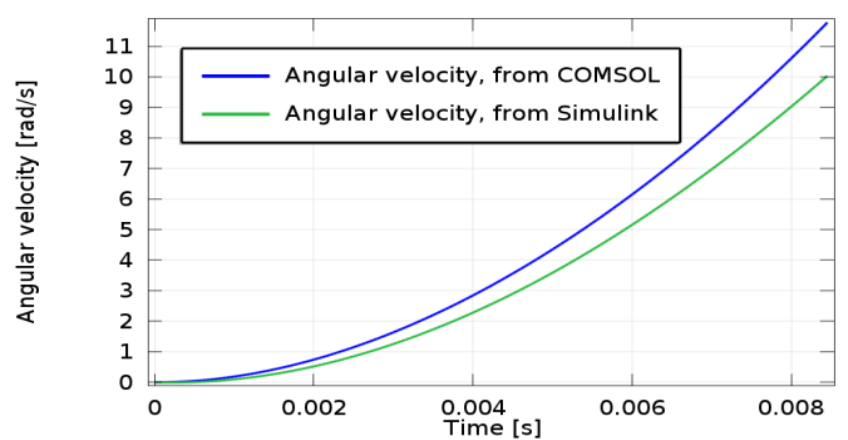

Fig. 15. Comparison of the input (from Simulink) and the speed calculated by COMSOL using inertia and torque.
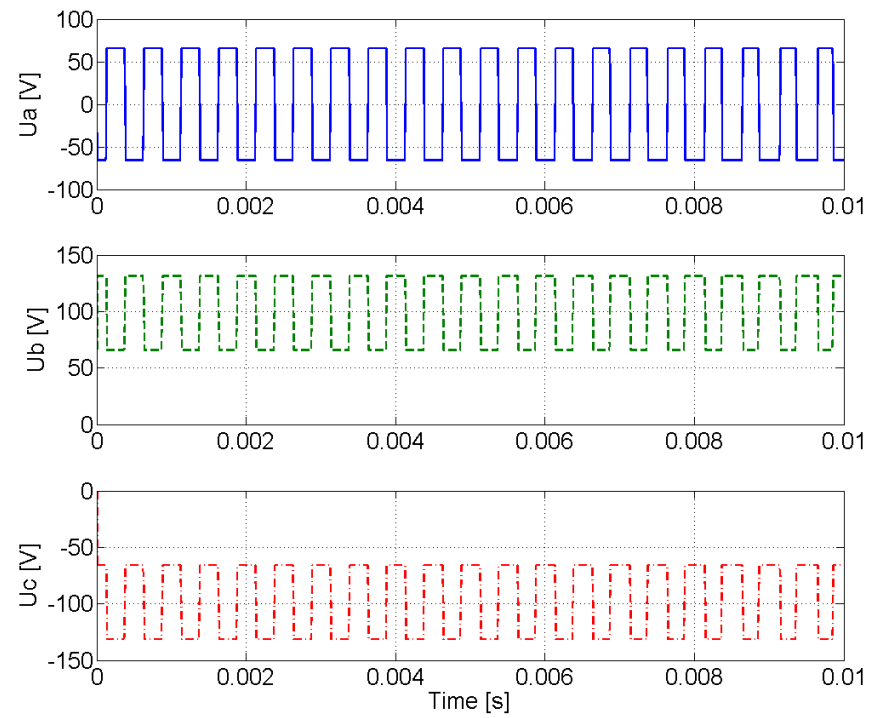

Fig. 16. Phase voltages from the Simulink model, a close-up in Fig. 12 Comparing to Fig. 14 does not show any difference therefore it can be concluded, that the coupling of the excitation functions properly.

As we compare figures Fig. 17 and Fig. 18 we can notice a slight difference in the calculated torques. We see that the torque in the finite element model is different, more precisely less, than the torque in the Simulink model. The difference between the models is more obvious looking at Fig. 15. This is where the angular velocities are shown. We can see that the speeds show an about $20 \%$ difference all along the time axis. Thus this is a systematic error.

The explanation to the observable difference in the Simulink and COMSOL calculated speed and torque is that the Simulink model included a small mechanical damping, as an inherent part of the synchronous motor model. This damping however, was not included in the finite element COMSOL model. That is the most likely reason why the results of the two simulation models differ from each other.
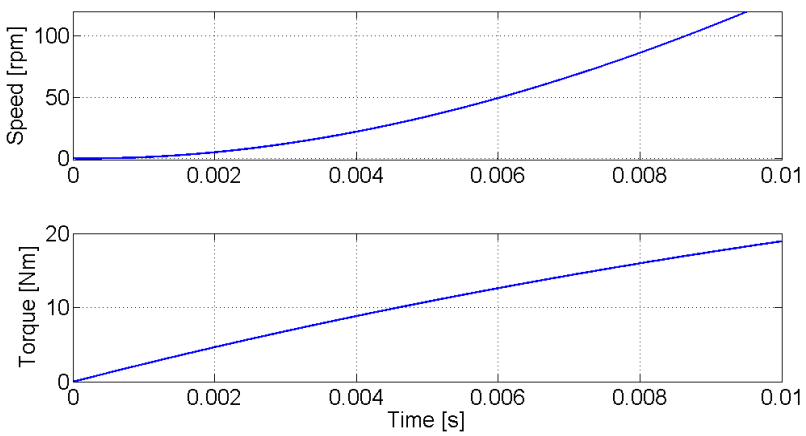

Fig. 17. Rotational speed and torques from the Simulink model, a close-up in Fig. 11 for comparison of rotational velocity of Fig. 15 and torque of Fig. 18. Please note, that here the speed is in unit [rpm] whereas in Fig. 15 the unit is $[\mathrm{rad} / \mathrm{s}]$.

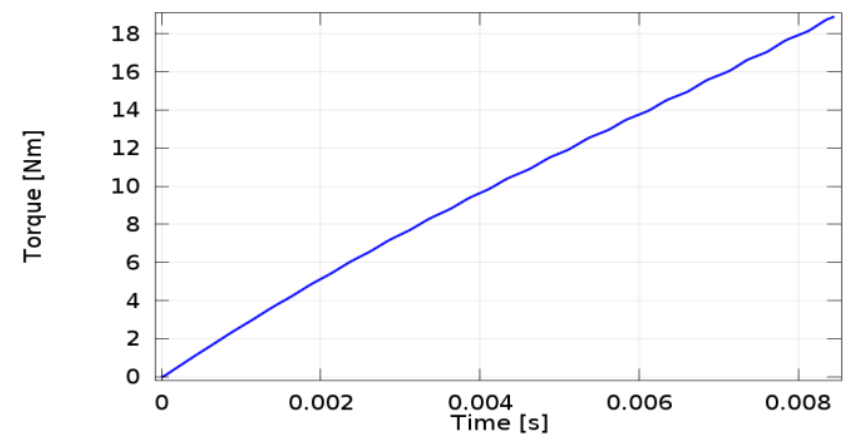

Fig. 18. Calculated torque from the coupled COMSOL model.

\section{CONCLUSION}

In this work a coupled modelling method for an inverter fed VSD has been presented. The modelling is based on COMSOL finite element software and MATLAB/Simulink.

The method enables the coupling of two different models via the results and parameters of the models thus enabling the modelling and simulation of a VSD in finite element environment. This allows for a deeper investigation of the consequences of inverter fed operation for a given device and can also be used to control the precision of the simpler Simulink model. It has been shown, that coupling can be done, and the fact that the results of different origin are in good agreement proves the viability of the method.

On the other hand a major drawback is the overall computational cost of the process. This results in long simulation times. This particular simulation of $10 \mathrm{~ms}$ inverter fed motor operation took 2 days using an Intel Core i7 @2.4 GHz CPU and 8 GB of RAM. This could be cured by using adequate computers for the task.

The method enables the coupling of two different models via the results and parameters of the models thus enabling the modelling and simulation of a VSD in finite element environment. This allows for a deeper investigation of the consequences of inverter fed operation for a given device and can also be used to control the precision of the simpler Simulink model. It has been shown, that coupling can be done, and the fact that the results of different origin are in good agreement proves the viability of the method. 


\section{REFERENCES}

[1] G. L. Skibinski, R. M. Tallam, M. Pande, R. J. Kerkman, D. W. Schlegel, "System design of adjustabel speed drives, part 1 \& 2", IEEE Industry Applications Magazine, Vol. 18, No. 4, Aug., 2012, ISSN 1077-2618.

[2] S. Halász, M. Hunyár, I. Schmidt, Automatizált Villamos Hajtások, Egyetemi tankönyv, ISBN $96342056310 ̈$, Müegyetemi kiadó, 1998

[3] N. Mohan, T. M. Underland, W. P. Robins, Power Electronics: Converters, Applications and Design, John Wiley \& Sons. New York. 1989.

[4] J. Liska, Villamos gépek, III. Szinkron gépek, Tankönyvkiadó Budapest 1955.

[5] MATLAB 2012b, Product help

[6] COMSOL Multiphysics, LiveLink for MATLAB, User's guide, Version 4.3

[7] COMSOL Multiphysics, AC/DC Module User's Guide

[8] C. Schulte and J. Bocker, "Co-Simulation of an Electric Traction Drive", E-ISBN 978-1-4673-4973-4, Electric Machines \& Drives Conference (IEMDC), 2013 IEEE International

[9] G. Almandoz, J. Poza, M. Ángel Rodríguez, A. González, "Co-Simulation Tools for the Permanent Magnet Machine Design Oriented to the Application", EUROCON, 2007. The International Conference on \&\#34; Computer as a Tool\&\#34, E-ISBN 978-1-4244-0813-9

[10] J. Legranger, G. Friedrich, S. Vivier, J. C. Mipo, "Combination of FiniteElement and Analytical Models in the Optimal Multidomain Design of Machines Application to an Interior Permanent-Magnet Starter Generator", IEEE Transactions On Industry Applications, Vol. 46, No. 1, 2010 http://dx.doi.org/10.1109/TIA.2009.2036549

[11] M. A. Jabbar, Z. Liu, J. Dong, "Time-Stepping Finite-Element Analysis for the Dynamic Performance of a Permanent Magnet Synchronous Motor", IEEE Transactions On Magnetics, Vol. 39, No. 5, 2003 http://dx.doi.org/10.1109/TMAG.2003.816500

[12] C. Favre, B. du Peloux, "Modelling of a Scalar Control of an Induction Machine Using Flux / Portunus Co-simulation", Flux Solutions \& Mechatronic Products, No. 61, 2011

[13] A. Daanoune, A. Foggia, L. Garbuio, J. C. Mipo, L. Li, "Modeling and optimal control of a hybrid excitation synchronous machine by combining analytical and finite element models", Electrical Machines (ICEM), 2012

[14] P. Kuo-Peng et al., "A General Method for Coupling Static Converters with Electromagnetic Structures," IEEE Trans. Magn., 1997 http://dx.doi.org/10.1109/20.582695

[15] S. Seman et al., "Performance Study of a Doubly Fed Wind-Power Induction Generator Under Network Disturbances," IEEE Trans. Energy Convers., 2006.

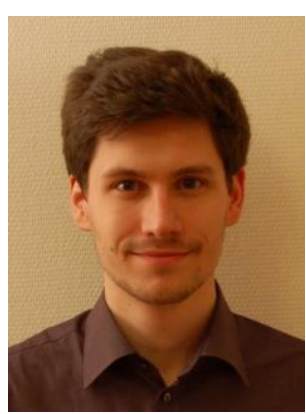

Gergely Máté Kiss, MSc, doctoral student.

$\mathrm{He}$ received his $\mathrm{MSc}$ degree in mechatronic engineering in 2013. Currently he is a doctoral student of Budapest University of Technology and Economics at the Department of Electric Power Engineering.

In 2011-2012 he has been working for GE Hungary as an intern with main responsibilities including controlling of technical drawings, preparing quality documentations and communication with suppliers and the engineering team in Finland.

In 2013 ha has been working for Audi Hungaria Motor as an intern where he was developing electric drive simulation models and preparing the construction of an inverter drive.

From 2013 he is a doctoral student at the Department of Electric Power Engineering and his main research field is the finite element modeling and design of electric rotating machines and inverter drives.

Postal address: 1111 Budapest, Egry J. u. 18., V1. épület, IV. em, Budapest, H-1521.

E-mail: kiss.gergely@vet.bme.hu

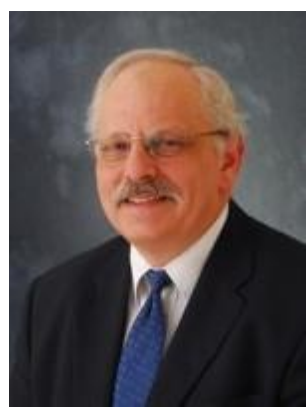

István Vajda, professor, (CSc, $\mathrm{PhD}, \mathrm{DSc}$, dr. habil). He is from Obuda University, director of Institute of Automation, and as a part-time professor working with the Department of Electric Power Engineering, Budapest University of Technology and Economics.

$\mathrm{He}$ is the leader of the SuperTech Laboratory. Fields of research: Large scale applications of superconductivity, Theory and design of electrical machines, Engineering problem solving. Nonconventional energy conversion. Internationally acknowledged scientist and expert in large scale applications of superconductivity. $\mathrm{He}$ is a representative of doctors Hungarian Academy of Sciences, president of the Electrotechnical Scientific Committee of HAS, IEEE member, vice-chair of IEEE Hungarian section, member and chair of the Scientific Committee of the Hungarian Electrotechnical Association, member of the Hungarian Academy of Engineers.

Postal address: Óbuda University, Kandó Kálmán Electrical Engineer Faculty, 1034 Budapest, Bécsi út 94-96.

Phone: +36 (1) 666-5801

E-mail: vajda.istvan@kvk.uni-obuda.hu 